Spergel, G., Bleichncr, S. J., and Ertel, N. H. (1968). Nere England fournal of Medicine, 278, 803 .

Svedmyr, N. (1967). Acta Pharmacologica et Toxicologica, 25, Suppl. No. 4, p. 29.

Taylor, S. H., et al. (1969). Lancet, 2, 1373.

Taylor, S. H., Majid, P. A., and Sharma, P. (1970a). Postgraduate Medical fournal. In press.

Taylor, S. H., et al. (1970b). British Heart fournal. In press.

Taylor, S. H., Majid, P. A., Saxton, C., and Stoker, J. B. (1970c). Neqv Zealand Medical fournal. In press.
Taylor, S. H., Sutherland, G. R., Mackenzie, G. J., Staunton, H. P., and Donald, K. W. (1965a). Circulation, 31, 741.

Taylor, S. H., Sutherland, G. R., Mackenzie, G. J., Staunton, H. P., and Donald, K. W. (1965b). Clinical Science, 28, 265.

Ulrych, M., Frohlich, E. D., Dustan, H. P., and Page, I H. (1968). Circulation, 37 ., Froh

Weissler, A. M., et al. (1968). Fournal of Clinical Investigation, 47, 403.

Weissler, A. M., Leonard, J. J., and Warren, J. V. (1959). fournal of Labora tory and Clinical Medicine, 53, 921

Wilber, J. I., Turtle. J. R., and Crane, N. A. (1966). Lancet, 2, 733

\title{
Further Observations on the Diurnal Variation in Oral Glucose Tolerance
}

\author{
R. J. JARRETT, ${ }^{*}$ M.D. ; H. KEEN, $†$ M.B., M.R.C.P.
}

\begin{abstract}
Summary: Diurnal variation in oral glucose tolerance was studied in 122 male volunteers aged 40 years and over who participated in a screening health examination. In those with screening blood sugar levels exceeding $110 \mathrm{mg} . / 100 \mathrm{ml}$. the degree of diurnal variation was least in those with the highest morning glycaemia; the latter also tended to have lower afternoon fasting blood sugar levels.

In a group of 40 control subjects, afternoon glucose tolerance tests yielded significantly higher post-glucose blood sugar levels. The degree of diurnal variation was significantly and inversely related to the degree of obesity.
\end{abstract}

\section{Introduction}

The phenomenon of diurnal variation of glucose tolerance in man has been described by several authors (Roberts, 1964; Bowen and Reeves, 1967; Jarrett and Keen, 1969), but little is known about the factors influencing this variation or about its relation to pathological carbohydrate intolerance and diabetes mellitus. We have taken the opportunity provided by a recent health survey of London civil servants to examine further some of the related factors.

\section{Methods}

The health survey, conducted in conjunction with the Department of Medical Statistics and Epidemiology, London School of Hygiene and Tropical Medicine, was open to male civil servants aged 40 and over and working in various Government departments in London. Volunteers were seen between 9.30 a.m. and 1 p.m., having fasted overnight and having drunk $50 \mathrm{~g}$. of liquid glucose $(235 \mathrm{ml}$. of Lucozade) one hour and fifty minutes before attending the screening clinic. Two hours after taking the glucose drink a capillary blood sample $(0.1 \mathrm{ml}$.) was taken from the ear lobe and added to $0.9 \mathrm{ml}$. of $1 \%$ potassium fluoride, and the blood sugar was estimated by the ferricyanide reduction micro-method (Technicon method $\mathrm{N}-9 \mathrm{a}$ ) on the AutoAnalyzer.

The usual survey practice was to carry out standard oral glucose tolerance tests on subjects with screening blood sugar levels of $110-199 \mathrm{mg} . / 100 \mathrm{ml}$. and to refer those with levels of $200 \mathrm{mg} . / 100 \mathrm{ml}$. or more to their personal doctors. For a period of about six months, however, all those with screening levels of $110 \mathrm{mg} . / 100 \mathrm{ml}$. or more, including those exceeding $200 \mathrm{mg} . / 100 \mathrm{ml}$, were recalled for a full glucose tolerance test; they were further asked if they would consent to a second test for the present research project. Though most $(96 \%)$ consented to the second test, difficulties in arranging convenient appointments reduced the overall response to $85 \%$ (122 subjects).

A random sample of subjects with screening blood sugars below $110 \mathrm{mg} . / 100 \mathrm{ml}$., stratified for age and two-hour blood sugar level, was selected as a control group, and those concerned were asked to participate in the research project Replies were received from 68 of the 81 people approached. Twenty-eight of these were either unable or unwilling to participate, so that $\mathbf{4 0}$ subsequently had the two glucose tolerance tests.

The morning and afternoon tests were performed in random order not less than three or more than seven days apart and after three days of supplementation of the normal daily diet with an extra $150 \mathrm{~g}$. of carbohydrate. The morning test began, after an overnight fast, at 9.30 a.m. The afternoon test started at 4 p.m., the subjects having fasted since a light breakfast, which in most cases had been completed by 8 a.m. Capillary blood samples were obtained before a $50 \mathrm{~g}$. load of liquid glucose and subsequently at half-hourly intervals for two hours. Subjects remained seated and did not smoke during the test period. Blood sugars were estimated as before.

The area under the glucose tolerance curve was calculated from the formula: area $=a+2 b+2 c+2 d+e$, where $a$ is the fasting blood sugar and $b-e$ are the subsequent blood sugar values.

In addition, the possible influence of diurnal variation on screening blood sugar values was examined. Those attending the usual morning survey sessions for a one-week period in January 1970 were asked to volunteer for an extra afternoon screening test, when two-hour blood sugars were estimated on samples collected between 5 and 6 p.m., the glucose having been drunk after fasting from breakfast. In this study, for which no special dietary preparations were made, 107 men participated.

\section{Results}

\section{Control Group}

The mean glucose tolerance test results are presented in Table I. The results are similar to, though not identical with, those in our earlier "normal" sample (Jarrett and Keen, 1969), which, however, was younger, was composed of both sexes, and in which the afternon tests were performed at 1 p.m., after a shorter, four to five hours, fast. In both studies the fasting blood sugar values, morning and afternoon, were virtually identical. In the previous series a significant excess of afternoon over morning values was already apparent 30 minutes after the glucose load, was numerically greater at 60 and 90 minutes, but was less at 120 minutes. In the present study there was little difference between morning and afternoon values at 30 minutes, but there was still a considerable and significant difference at 120 minutes. 
The interrelationship of obesity, expressed as the ponderal index, with the degree of diurnal variation in glucose tolesance is shown in Table II. The ponderal index (height in inches divided by the cube root of weight in pounds) is a good index of obesity (Steinkamp et al., 1965), the highest numerical values occurring in the least obese. The group was divided into three tertiles of distribution of ponderal indexhigh, medium, and low-and the mean glucose tolerance test area calculated separately for both morning and afternoon tests. Clearly the morning "area" increases with increasing degrees of obesity. The statistical significance of this relationship was calculated by performing a linear correlation analysis between the ponderal index and the difference between morning and afternoon glucose tolerance areas-that is the diurnal swing. The correlation coefficient was $0.464(\mathrm{p}<0.001)$.

The degree of diurnal variation in relation to the degree of morning glycaemia is shown in Table III. While there is some diminution of diurnal swing with increasing morning glucose tolerance area, the effect is considerably less than that observed with increasing obesity (Table II). The interrelationship of age and diurnal variation is examined in Table IV. Neither morning nor afternoon glucose tolerance

TABLE I.-Mean ( \pm S.E. of Mean) Blood Sugar Levels in Morning and Afternoon Glucose Tolerance Tests in the Control Group

\begin{tabular}{|c|c|c|c|c|c|c|c|}
\hline & & & \multicolumn{5}{|c|}{ Time (Minutes) } \\
\hline & & & 0 & 30 & 60 & 90 & 120 \\
\hline $\begin{array}{l}\text { Morning } \\
\text { Afternoon }\end{array}$ & $\begin{array}{l}\cdots \\
\ldots\end{array}$ & $\begin{array}{l}\cdots \\
\cdots\end{array}$ & $\begin{array}{l}72.93 \\
\pm 1.38 \\
73.93 \\
\pm 1.30\end{array}$ & $\begin{array}{r}128.92 \\
\pm 4.30 \\
131.63 \\
\pm 3.32\end{array}$ & $\begin{array}{l}130.65 \\
\pm 4.48 \\
161 \cdot 60 \\
\pm 6.12\end{array}$ & $\begin{array}{r}95 \cdot 20 \\
\pm 4 \cdot 15 \\
145 \cdot 18 \\
\pm 3 \cdot 39\end{array}$ & $\begin{array}{r}69.03 \\
\pm 2.88 \\
104.98 \\
+4.64\end{array}$ \\
\hline Difference & .. & $\ldots$ & 1.0 & $2 \cdot 71$ & $30 \cdot 95$ & 49.98 & 35.95 \\
\hline
\end{tabular}

TABLE II.-Comparison of Morning and Afternoon Glucose Tolerance Areas (Mean \pm S.E. of Mean) by Tertile of Ponderal Index in the Control Group

\begin{tabular}{|c|c|c|c|c|c|c|}
\hline \multirow{2}{*}{\multicolumn{2}{|c|}{ Mean Ponderal Index }} & & \multirow[t]{2}{*}{ No. } & \multicolumn{2}{|c|}{$\begin{array}{c}\text { Mean } \pm \text { S.E. of Mean } \\
\text { Glucose } \\
\text { Tolerance Area }\end{array}$} & \multirow[t]{2}{*}{ Difference } \\
\hline & & & & A.M. & P.M. & \\
\hline $\begin{array}{l}13.15 \text { (high) } \\
12.70 \text { (medium) } \\
11.20 \text { (low) }\end{array}$ & & $\begin{array}{l}\cdots \\
\therefore\end{array}$ & $\begin{array}{l}13 \\
14 \\
13\end{array}$ & $\begin{array}{l}796 \pm 29 \\
825 \pm 30 \\
914 \pm 47\end{array}$ & $\begin{array}{l}1,116 \pm 58 \\
1,048 \pm 40 \\
1,024 \pm 37\end{array}$ & $\begin{array}{l}320 \\
223 \\
110\end{array}$ \\
\hline
\end{tabular}

TABLE III.-Results of Morning and Afternoon Glucose Tolerance Tests in Normal Group Divided into Tertiles of Distribution of Morning Glucose Tolerance Test Area

\begin{tabular}{|c|c|c|c|c|c|c|}
\hline \multirow[t]{2}{*}{ Mean } & \multirow{2}{*}{\multicolumn{2}{|c|}{ Ponderal Index }} & \multirow{2}{*}{$\begin{array}{c}\text { Glucose Tolerance } \\
\text { Area Tertile }\end{array}$} & \multicolumn{2}{|c|}{$\begin{array}{l}\text { Mean Glucose } \\
\text { Tolerance Area }\end{array}$} & \multirow[t]{2}{*}{ Difference } \\
\hline & & & & A.M. & P.M. & \\
\hline $\begin{array}{l}12 \cdot 86 \\
12 \cdot 58 \\
12 \cdot 47\end{array}$ & $\begin{array}{l}\cdots \\
\cdots\end{array}$ & $\begin{array}{l}\cdots \\
\cdots \\
\cdots\end{array}$ & $\begin{array}{cc}<775 & (n=13) \\
775-885 & (n=14) \\
>885 & (n=13)\end{array}$ & $\begin{array}{l}712 \\
827 \\
995\end{array}$ & $\begin{array}{r}960 \\
1,078 \\
1,147\end{array}$ & $\begin{array}{l}248 \\
251 \\
152\end{array}$ \\
\hline
\end{tabular}

TABLE IV.-Comparison of Morning and Afternoon Glucose Tolerance Area by Age Group in the Control Group

\begin{tabular}{c|c|c|c|c}
\hline Age Group & No. & A.M. & P.M. & Difference \\
\hline $40-49$ & 18 & $868 \cdot 0 \pm 34$ & $1,054 \cdot 0 \pm 31$ & 186 \\
$50-59$ & 14 & $830.0 \pm 34$ & $1,110 \cdot 0 \pm 50$ & 280 \\
$60+$ & 8 & $815 \cdot 0 \pm 51$ & $996.0 \pm 52$ & 181 \\
\hline
\end{tabular}

TABle V.-Mean ( \pm S.E. of Mean) Blood Sugar Levels in Morning and Afternoon Glucose Tolerance Tests in the Hyperglycaemic Group

\begin{tabular}{|c|c|c|c|c|c|c|c|}
\hline & & & \multicolumn{5}{|c|}{ Time (Minutes) } \\
\hline & & & $\mathbf{0}$ & 30 & 60 & 90 & 120 \\
\hline $\begin{array}{l}\text { Morning } \\
\text { Afternoon }\end{array}$ & $\begin{array}{l}\cdots \\
\cdots\end{array}$ & $\begin{array}{l}\cdots \\
\ldots\end{array}$ & $\begin{array}{l}99.52 \\
\pm 3.02 \\
91.29 \\
\pm 3.13\end{array}$ & $\begin{array}{r}177 \cdot 80 \\
\pm 4 \cdot 15 \\
172 \cdot 85 \\
\pm 4 \cdot 09\end{array}$ & $\begin{array}{r}194.88 \\
\pm 5.82 \\
210 \cdot 56 \\
\pm 4.80\end{array}$ & $\begin{array}{l}156 \cdot 0 \\
\pm 5.84 \\
178 \cdot 19 \\
\pm 4.80\end{array}$ & $\begin{array}{r}122.61 \\
\pm 5.15 \\
141.13 \\
\pm 4.63\end{array}$ \\
\hline
\end{tabular}

areas increase with age; nor is there any apparent trend in the differences between morning and afternoon values.

\section{Hyperglycaemic (Positive Screening) Group}

The mean results of the two glucose tolerance tests in subjects screening with two-hour blood sugars in excess of 109 $\mathrm{mg} .100 \mathrm{ml}$. are presented in Table $\mathrm{V}$ and the influence of obesity and age is shown in Tables VI and VII. Like the normoglycaemic group, the morning glucose tolerance area increases with the increasing degree of obesity and the difference between moming and afternoon values is inversely related to the degree of obesity. Linear correlation of ponderal index and the diurnal difference, however, proved not significant $(r=0.075)$.

Both morning and afternoon glucose tolerance areas increase with age, but the difference between morning and afternoon values shows no clear relationship with age. The mean morning and mean afternoon glucose tolerance test results are compared in the chart after the subjects have been divided into subgroups according to the level of the two-hour blood sugar in the morning test. Evidently the degree of diurnal variation diminishes as morning hyperglycaemia increases. Furthermore, in the more hyperglycaemic groups the fasting blood sugar level in the afternoon is appreciably, and in several groups significantly, lower than that after the overnight fast.

\section{Diurnal Variation and Test Results}

Two systems of diagnostic classification have been applied. The first (Table VIII) classifies as normal those tests in which the peak blood sugar is $180 \mathrm{mg} . / 100 \mathrm{ml}$. or less and the two-hour blood sugar is $120 \mathrm{mg} . / 100 \mathrm{ml}$. or less, which is the classification recommended by the Medical and Scientific Section of the British Diabetic Association (Fitzgerald and Keen, 1964). All the control group had normal morning tests, but $10(25 \%)$ had abnormal afternoon tests. The detailed results for these 10 subjects are given in Table IX. Of the 71 men in the hyperglycaemic group with normal morning tests, 27 (36.6\%) had abnormal afternoon tests. In contrast, of 51 with abnormal

TABL.E VI.-Comparison of Morning and Afternoon Glucose Tolerance Area by Tertile of Ponderal Index in the Hyperglycatmic Group

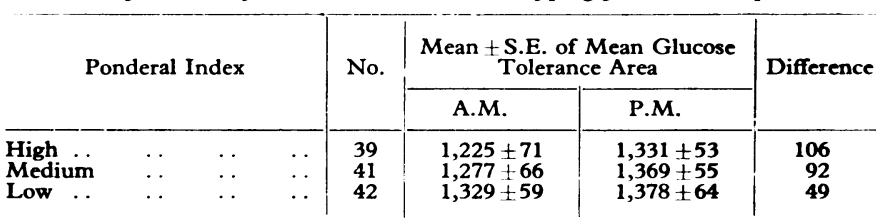

Table VII.-Comparison of Morning and Afternoon Glucose Tolerance Area by Age Group in the Hyperglycaemic Group

\begin{tabular}{c|c|c|c|c}
\multirow{2}{*}{ Age Group } & No. & \multicolumn{2}{|c|}{$\begin{array}{c}\text { Mean } \pm \text { S.E. of Mean Glucose } \\
\text { Tolerance Area }\end{array}$} & \multirow{2}{*}{ Difference } \\
\cline { 2 - 4 } & & A.M. & P.M. & \\
\hline $40-49$ & 23 & $1,096 \pm 57$ & $1,187 \pm 49$ & 91 \\
$50-59$ & 53 & $1,265 \pm 54$ & $1,321 \pm 40$ & 56 \\
$60+$ & 46 & $1,385 \pm 67$ & $1,491 \pm 67$ & 106
\end{tabular}

TABLE VIII.-Classification of Glucose Tolerance Tests into Two Categories. See Text for Criteria

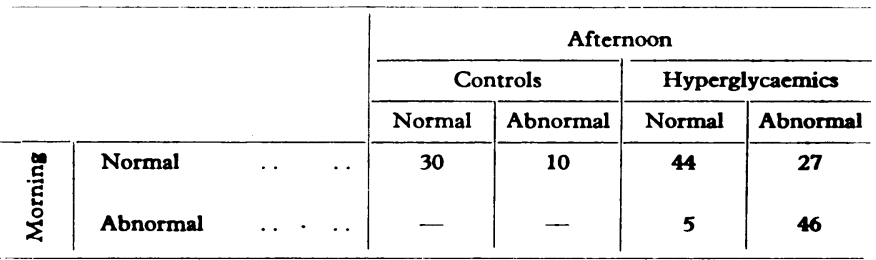


TABLE IX.-Morning and Afternoon Glucose Tolerance Test Results for the 10 Individuals with Abnormal Afternoon Tests by the British Diabetic Association Criteria (Table VIII)



morning tests, all but five also had abnormal tests in the afternoon.

The second classification (Table $\mathrm{X}$ ) is one suggested by the European Diabetes Epidemiology Study Group (Jarrett, 1970), and this divides the response to glucose into three categories: (1) normal response to glucose (N.R.G.)-peak blood sugar level and two-hour blood sugar level less than 161 and 121 mg./100 ml., respectively; (2) pathological response to glucose (P.R.G.) - peak blood sugar level and two-hour blood sugar level more than 219 and $149 \mathrm{mg} . / 100 \mathrm{ml}$., respectively; and (3) borderline response to glucose (B.R.G.)-combinations of peak and two-hour blood sugar levels not falling in category 1 or 2 .

The results from this classification were broadly similar, with more borderline and pathological responses occurring in the afternoon.

TABLE X.-Classification of Glucose Tolerance Tests into Three Categories. See Test for Criteria.

\begin{tabular}{|c|c|c|c|c|c|c|c|c|}
\hline & & & \multicolumn{6}{|c|}{ Afternoan } \\
\hline & & & \multicolumn{3}{|c|}{ Controls } & \multicolumn{3}{|c|}{ Hyperglycaemics } \\
\hline & & & N.R.G. & B.R.G. & P.R.G. & N.R.G. & B.R.G. & P.R.G. \\
\hline 률 & $\begin{array}{l}\text { N.R.G. } \\
\text { B.R.G. } \\
\text { P.R.G. }\end{array}$ & \begin{tabular}{l|l}
$\ldots$ & \\
$\cdots$ &
\end{tabular} & $\underline{14}$ & $\begin{array}{r}18 \\
7 \\
-\end{array}$ & $\frac{1}{-}$ & $\begin{array}{r}8 \\
3 \\
-\end{array}$ & $\begin{array}{r}26 \\
43 \\
7\end{array}$ & $\begin{array}{r}1 \\
10 \\
24\end{array}$ \\
\hline
\end{tabular}

\section{Diurnal Variation and Screening Levels}

In the group of 107 men in whom the two-hour blood sugars were measured under screening conditions there was little difference between the mean level of blood sugar in the morning $(76.5 \mathrm{mg} . / 100 \mathrm{ml}$.) and that in the afternoon (79.1 mg./100 ml.). There was, however, much more variation in the afternoon levels, the standard deviation being $20.6 \mathrm{mg}$./ $100 \mathrm{ml}$. against $7.5 \mathrm{mg} . / 100 \mathrm{ml}$. in the morning.

\section{Discussion}

We have previously discussed (Jarrett and Keen, 1969) the possible general implications of the diurnal rise in blood sugar levels in response to an oral glucose load. In particular, we feel strongly that, in critical instances, it is not valid to assume normal glucose homoeostasis on the basis of one or even more than one normal standard morning test. Clearly, a considerable degree of hyperglycaemia may occur in the afternoon in the presence of unequivocally normal morning tests, and the findings in our "normal screening" group suggest that this may occur in a quarter of the subjects examined. The potential importance of this lies in the relationship beween hyperglycaemia and the prevalence and subsequent incidence of atherosclerotic arterial disease (Keen and Jarrett, 1969). At present there is insufficient information available to determine whether the same relationship exists with afternoon hyperglycaemia. Clearly this is an area for further exploration on an epidemiological scale, and it is to be hoped that it may form part of the experimental design of future studies concerned with this relationship.

Evidently, a relatively hyperglycaemic response in the afternoon must be regarded as a normal phenomenon, occurring in most normoglycaemic subjects, but raising the blood sugar to the conventionally hyperglycaemic range in about a quarter. It is, inevitably, reminiscent of the cortisol-stressed response to glucose, and it would be of great interest to know whether those subjects who show the greatest diurnal swing are also those who respond most strongly to cortisol.

In contrast, the dimensions of the diurnal swing lessen with increasing degrees of (morning) glucose intolerance. This perhaps indicates a progressive impairment of the capacity to restore the afternoon "relaxation" of glucose homoeostasis to normal during the night. It is these subjects with morning hyperglycaemia who also tend to have lower afternoon fasting blood sugar levels. This might represent the phenomenon of late hypoglycaemia after oral glucose, described as an early manifestation of the disordered insulin release which culminates in clinical diabetes (Seltzer et al., 1959; Faludi et al.,

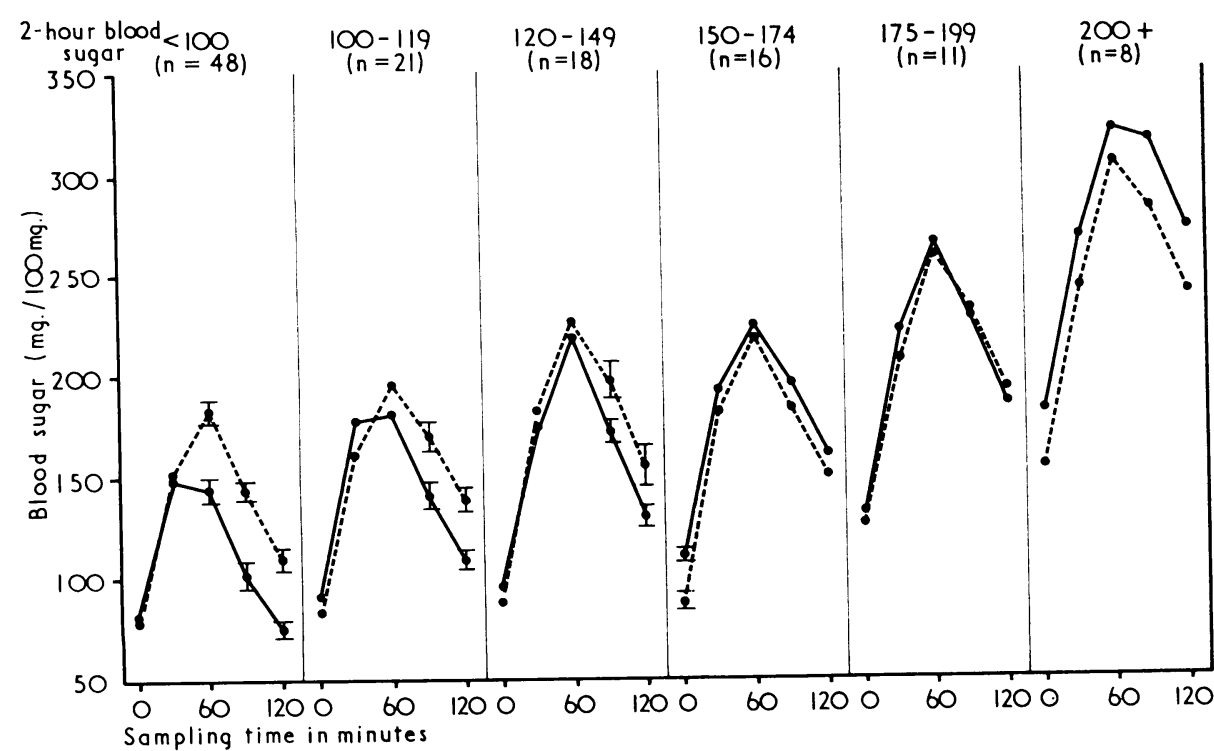

Mean blood sugar levels in morning (solid line) and afternoon (interrupted line) glucose tolerance tests in the positive screening individuals. The six groups are categorized by the level of the two-hour blood sugar in the morning test a difference significant at 1 in 20 . 
1968). Alternatively, it may represent the diurnal variation in fasting blood sugar levels in established diabetics shown by Faiman and Moorhouse (1967). These workers reported that during three-day fasts five diabetic subjects showed a diurnal cycle in their blood glucose levels, with the peak levels occurring around 8 a.m.; no such cycle could be discerned in five healthy controls.

The inverse relation of obesity, as measured by the ponderal index, with the degree of diurnal variation in glucose tolerance, was significant only in the normoglycaemic group, but was also evident in the hyperglycaemic group. Since the morning glucose tolerance area is itself associated directly with the degree of obesity, it is difficult to decide how much of the loss of diurnal variation to attribute to obesity per se and how much to the associated hyperglycaemia. The analyses of the control group in Tables II and III, however, suggest that obesity is the more potent factor when morning glycaemia is within the normal range and is perhaps an independent one.

Diagnostic classification of the tests yields many abnormalities by afternoon testing in the group preselected for normoglycaemia. By one system of classification (Table VIII) all the morning tests were normal, but 10 afternoon tests were abnormal. Table IX lists the paired tests in these 10 subjects, and in all but one (No. 2) the morning tests are unequivocally normal. In some, however, the diurnal swing is so greatfor example, Nos. 6, 7, and 9-as to bring the test results into what most would regard as the conventionally diabetic range. The present and potential significance of this phenomenon can only be hypothetical. This exaggerated swing may possibly represent an earler stage in the failure of glucose homoeostasis than the reduced swing seen in those with morning hyperglycaemia. Obviously, only longitudinal studies can provide the answer, and these are fraught with difficulties, not least logistical ones. A suggested working hypothesis, however, is that afternoon hyperglycaemia is the first stage of glucose intolerance, followed by increased morning glycaemia (and reduced diurnal variation), then proceeding to morning hyperglycaemia, sufficient eventually to warrant the description of diabetes mellitus.

The small diurnal difference in mean two-hour blood sugar levels measured under screening conditions agrees with our previous experience (Keen, 1966) and presumably accounts for the failure of others to find diurnal variation in population surveys (Hayner et al., 1965; Marine et al., 1969). The reason for the relative lack of diurnal variation under these conditions is probably related to the lesser degree of standardization obtaining. Though the mean blood sugar levels were similar, the variation was very much greater in the afternoon, so that afternoon screening would be likely to yield more subjects exceeding an arbitrary cut-off level.

We are grateful to the many men who volunteered to participate in this study, and to our colleagues at the London School of Hygiene for their co-operation. Our contribution to the main survey and follow-up is financed by a grant from the Department of Health and Social Security. R. J. J. wishes to thank Lilly Laboratories for additional financial support.

\section{REFERENCES}

Bowen, A. J., and Reeves, R. L. (1967). Archives of Internal Medicine, 119

Faiman, C., and Moorhouse, J. A. (1967). Clinical Science, 32, 111.

Faiman, C., and Moorhouse, J. A. (1967). Clinical Science, 32, 111.
Faludi, G., Bendersky, G., and Gerber, P. (1968). Annals of the New York Academy of Sciences, 148, 868.

Fitzgerald, M. G., and Keen, H. (1964). British Medical fournal, 1, 1568.

Hayner, N. S., Kjelsberg, M. O., Epstein, F. H., and Francis, T., jun (1965). Diabetes, 14, 413.

Jarrett, R. J. (1970). Diabetologia. 6, 453.

Jarrett, R. J., and Keen, H. (1969). British Medical fournal, 2, 341

Keen, H. (1966). Proceedings of the Royal Society of Medicine, 59, 1169. Keen, H., and Jarrett, R. J. (1969). Proceedings of the 2nd International Symposium on Atherosclerosis. In press.

Marine, N., Vinik, A. I., Edelstein, I., and Jackson, W. P. U. (1969) Diabetes, 18, 840 .

Roberts, H. J. (1964). Fournal of the American Geriatrics Society, 12, 423.

Seltzer, H. S., Fajans, S. S., and Conn, J. W. (1959). Diabetes, 5, 437.

Steinkamp, R. C., et al. (1965). Fournal of Chronic Diseases, 18, 1291.

\title{
Exercise Asthma and Disodium Cromoglycate
}

\author{
H. POPPIUS, ${ }^{*}$ M.D. ; A. MUITTARI, ${ }^{*}$ M.D. ; K.-E. KREUS, $†$ M.D. \\ O. KORHONEN, $†$ M.D. ; A. VILJANEN, $†$ M.D.
}

\begin{abstract}
Cummary: Exercise-induced asthma (defined as a fall in PEF of at least $25 \%$ of the pre-exercise value) was studied in adult patients with uncomplicated asthma. This was found to occur in 22 out of 52 patients. Preexercise inhalation of disodium cromoglycate reduced the mean fall in PEF after maximal exercise from $50 \%$ of the pre-exercise value to $23 \%$ (open assessment in 11 cases). After submaximal exercise for eight minutes the reduction was from $18 \%$ to $10 \%$ (double-blind crossover study in 28 cases). It is concluded that disodium cromoglycate partly inhibits the increase of airways resistance after exercise in asthmatic patients.
\end{abstract}

\section{Introduction}

In asthmatics heavy exercise over several minutes may be followed by an increase in airways resistance (Pearson, 1952; McNeill et al., 1966; Sly et al., 1967; Sly, 1970), which is inhibited by sympathomimetics but usually not by atropine or

\footnotetext{
* Senior lecturer, Department of Pulmonary Diseases, University Central
Hospital, Helsinki, Finland.

† Registrar, University Central Hospital, Helsinki.
}

cortisone (Jones et al., 1962; McNeill et al., 1966; Sly et al., 1967). The mechanism of the reaction has not been explained, though several suggestions and hypotheses have been presented (Seaton et al., 1969; Ward et al., 1969; Kerr et al., 1970).

Inhalation of disodium cromoglycate may inhibit the bronchoconstriction after inhalation provocation tests in patients with extrinsic asthma (Altounyan, 1967; Pepys et al., 1968; Muittari, 1969). Disodium cromoglycate is thought to block the mechanism by which bronchoconstrictive substances are released from mast cells after antigen-antibody reaction (Cox, 1967) or to inhibit the effect of pharmacologically active amines on bronchial smooth muscle or both (Kerr et al., 1970). Uncontrolled studies (Davies, 1968, Muittari and Kreus, 1969; Palmer and Legge, 1969; Ward et al., 1969) suggest that disodium cromoglycate may inhibit exercise-induced asthma. To our knowledge, however, no double-blind trials have been reported.

The purpose of the present study is (1) to estimate the prevalence, severity, and repeatability of exercise-induced asthma in inpatients with uncomplicated asthma and (2) to evaluate the effect of disodium cromoglycate on exerciseinduced asthma by using a double-blind cross-over technique. 